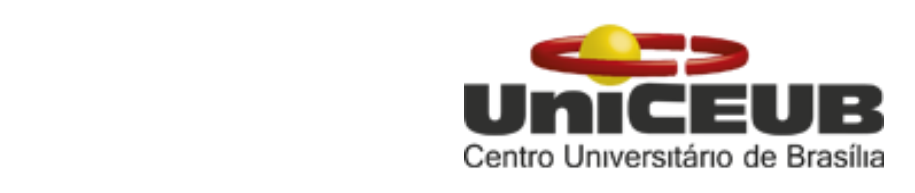

CENTRO UNIVERSITÁRIO DE BRASÍLIA - UnICEUB

FACULDADE DE CIÊNCIAS DA EDUCAÇÃO E DA SAÚDE - FACES

PROGRAMA DE INICIAÇÃO CIENTÍFICA

MARIANA FRANÇA BANDEIRA DE MELO

MARIANA CARVALHO GOMES

"AVALIAÇÃO CLÍNICA DO RISCO DE QUEDAS COM E SEM FRATURAS EM

PACIENTES COM NEUROPATIA DIABÉTICA"

BRASÍLIA

2017 


\section{บnट $=\mathrm{UB}$ \\ Centro Unıversıtárıo de Brasílıa}

\section{MARIANA FRANÇA BANDEIRA DE MELO MARIANA CARVALHO GOMES}

\section{“AVALIAÇÃO CLÍNICA DO RISCO DE QUEDAS COM E SEM FRATURAS EM PACIENTES COM NEUROPATIA DIABÉTICA"}

Relatório final de pesquisa de Iniciação Científica apresentado à Assessoria de Pós-Graduação e Pesquisa pela Faculdade de Ciências da Educação e da Saúde - FACES

Orientação: Dra. Gabriela Resende Vieira de Sousa 


\section{AGRADECIMENTOS}

Agradecemos ao auxílio e apoio da Dra. Lilian Assumpção Paes Leme, bem como da equipe do centro de saúde $n^{\circ} 9$ do Cruzeiro - DF, os quais sempre se mostraram prestativos e foram essenciais para o desenvolvimento dessa pesquisa. 


\title{
"AVALIAÇÃO CLÍNICA DO RISCO DE QUEDAS COM E SEM FRATURAS EM PACIENTES COM NEUROPATIA DIABÉTICA"
}

\author{
Mariana França Bandeira de Melo - UniCEUB, PIBIC-CNPq, aluno bolsista
}

marifrancabm@gmail.com

\section{Mariana Carvalho Gomes - UniCEUB, PIBIC-CNPq, aluno voluntário} carvalhogomesmari@gmail.com

\section{Gabriela Resende Vieira de Sousa - UniCEUB, professora orientadora} gabrirvsousa@gmail.com

Devido à alta incidência e prevalência na população brasileira, o Diabetes Mellitus tipo 2 (DM2) representa um problema de grande importância social e para a saúde pública. A polineuropatia diabética é umas das complicações crônicas mais graves do diabetes. Esse distúrbio é definido por sinais e sintomas de disfunção dos nervos periféricos em pacientes com DM2. A maior propensão a quedas nos pacientes diabéticos afeta enormemente a sua qualidade de vida, pois pode resultar em fraturas, diminuição da autonomia, declínio da mobilidade, evitação de atividades, hospitalizações e maior morbimortalidade. Os objetivos dessa pesquisa foram avaliar a prevalência de neuropatia diabética sensitivomotora associada ao risco de quedas com e sem fraturas em pacientes com DM2 que fazem acompanhamento no Centro de Saúde número 9 da Secretaria de Saúde do Distrito Federal (SES-DF), assim como suas características clínicas e sociais mais importantes. Além disso, correlacionar o risco de quedas com o grau de neuropatia diabética sensitivomotora e o controle glicêmico dos pacientes, e avaliar frequência de quedas e fraturas apresentadas por estes pacientes no ano anterior à avaliação. Os critérios de inclusão foram possuir o diagnóstico de DM2 e ter entre 50 e 70 anos. Foram excluídos os pacientes que apresentavam outras causas de neuropatia. Foram selecionados 40 participantes, os quais foram submetidos ao exame detalhado dos pés com a avaliação das sensibilidades dolorosa, vibratória, tátil, térmica e do reflexo aquileu, bem como avaliação de sensibilidade sensitiva através do teste de monofilamento. Então, foram submetidos a um teste já padronizado para screening de neuropatia diabética sensitivomotora periférica denominado "United Kingdom Screening Test" que permite identificar presença ou ausência de neuropatia, assim como classificá-la. Posteriormente foi realizada a avaliação do equilíbrio estático e dinâmico, com os testes "Berg and Balance Scale" (BSS) e o teste de mobilidade funcional "Timed Up and Go" (TUG). A prevalência de neuropatia sensitivomotora na amostra foi de $40 \%$ (43,75\% grau leve, $37,5 \%$ moderado e $18,75 \%$ grave), dado compatível com a prevalência desse problema na população diabética. Desses, $60 \%$ relataram ter sofrido queda no ano anterior, uma associação que tendeu a significância estatística $(p=0,1003)$. Nenhum desses pacientes apresentou fratura decorrente da queda. Comparando as características do grupo que teve quedas com o que não teve quedas, verificou-se que $63,3 \%$ dos que não apresentaram queda nunca fumaram, porém, ao 
analisar o grupo dos que apresentaram queda, $70 \%$ eram tabagistas (p: 0,025). Esse dado pode representar uma associação entre o hábito de fumar e a ocorrência de quedas em pacientes diabéticos tipo2 com neuropatia sensitivomotora periférica. Não houve relação entre o controle glicêmico e a incidência de quedas nesses pacientes, no entanto, essa avalição foi prejudicada pela indisponibilidade do exame de hemoglobina glicada na SES durante a execução da pesquisa.

Palavras-Chave: diabetes; neuropatia diabética; quedas; fraturas 


\section{INTRODUÇÃO}

Uma epidemia de diabetes mellitus tipo 2 (DM2) está em curso. Atualmente, estima-se que a população mundial com diabetes é de 382 milhões de pessoas e que deverá atingir 471 milhões em 2035 (1). Esse número está aumentando em virtude do crescimento e envelhecimento populacional, da maior urbanização, da crescente prevalência da obesidade e do sedentarismo. Devido à sua alta incidência e prevalência na população brasileira, o DM2 representa um problema de grande importância social e para a saúde pública (2).

A polineuropatia diabética (PND) é umas das complicações crônicas mais graves do diabetes. Esse distúrbio é definido por sinais e sintomas de disfunção dos nervos periféricos em pacientes com diabetes mellitus, nos quais outras causas foram excluídas (3). É a complicação crônica mais frequente entre os pacientes diabéticos, com prevalência estimada de $40-50 \%$ comparada com $25-30 \%$ da retinopatia e $20 \%$ da nefropatia. As PND incluem formas generalizadas simétricas que podem ser de origem sensitivomotora, autonômica e, mais raramente, sensorial aguda, enquanto as formas focais e multifocais são menos frequentes (4).

O diagnóstico requer uma avaliação clínica cuidadosa, uma vez que a ausência de sintomas não pode ser equacionada como ausência de neuropatia. Cerca de $10 \mathrm{a}$ $18 \%$ dos pacientes possuem algum grau de lesão neuronal periférica já no momento do diagnóstico do DM2, o que demonstra que mesmo alterações leves no metabolismo da glicose estão relacionadas com o desenvolvimento de neuropatia (4, 5). A PND diminui de forma importante o cuidado que o paciente tem com o diabetes e, consequentemente, resulta num pior prognóstico das outras complicações da doença. A falta de sensibilidade pode levar à ulceração e a infecções que culminam em amputações (6).

A forma mais comum das apresentações da PND é a forma sensitivomotora crônica (PNDS) que causa alterações sensitivas e motoras periféricas, as quais podem resultar em prejuízo da propriocepção e do equilíbrio dos acometidos. Os mecanismos envolvidos nessa instabilidade incluem: comprometimento de fibras motoras que afetam os músculos da marcha, anormalidades nos centros de pressão plantares, deformidades osteoarticulares, déficit sensitivo nos pés e redução dos reflexos posturais (7-9). Tudo isso leva a um risco aumentado de quedas nesses 
indivíduos, que pode ainda ser agravado por outras complicações da doença como retinopatia, afecção vestibular, alterações ósseas e presença de úlceras plantares (8). A maior propensão a quedas nos pacientes diabéticos afeta enormemente a sua qualidade de vida, pois podem resultar em fraturas, diminuição da autonomia, declínio da mobilidade, evitação de atividades, hospitalizações e maior morbimortalidade (10, 11). Ocorre, ainda, um importante custo para a saúde pública decorrente destes eventos. O SUS registra mais de $\mathrm{R} \$ 51$ milhões por ano com o tratamento de fraturas após quedas *1.

Um melhor controle glicêmico reduziria enormemente todo este quadro, através do retardo de complicações da doença, principalmente a neuropatia, mas também a retinopatia e as alterações ósseas, diminuindo, por consequência, o risco de quedas e de fraturas. No entanto, é importante que esses pacientes sejam vistos como população de risco e também se previnam de outras formas como redução no tabagismo, realização de atividades físicas regulares e também correção de deficiência de vitamina $D$ e/ou cálcio. Além disso, sabemos que existem medidas simples que podem ser introduzidas na rotina através da orientação por profissionais da área de saúde, as quais poderiam prevenir e diminuir o risco de quedas e fraturas nessa população de risco, melhorando a qualidade de vida e a morbimortalidade causada por essa patologia. No entanto, para programar políticas de saúde, é necessário conhecer de maneira detalhada a realidade econômico-política e social em que vivem os pacientes os quais visamos atingir e ter resultados positivos.

O objetivo deste estudo foi avaliar a prevalência de neuropatia diabética sensitivomotora associada ao risco de quedas com e sem fraturas em pacientes com diagnóstico de DM2 que fazem acompanhamento no Centro de Saúde número 9 da Secretaria de Saúde do Distrito Federal (SES-DF), assim como as características clínicas e sociais mais importantes desses pacientes. Além disso, correlacionar o risco de quedas com o grau de neuropatia diabética sensitivomotora e o controle glicêmico dos pacientes, e também avaliar a frequência de quedas e fraturas apresentadas por estes pacientes no ano anterior à avaliação.

\footnotetext{
${ }^{* 1}$ Disponível em: http://www.brasil.gov.br/saude/2012/04/quedas
} 


\section{FUNDAMENTAÇÃO TEÓRICA}

Neuropatia diabética é um distúrbio frequente entre os diabéticos, o qual é definido por sinais e sintomas de disfunção dos nervos periféricos em pacientes com diabetes mellitus, nos quais outras causas de disfunção dos nervos periféricos foram excluídas (3). É a complicação mais comum do diabetes, com prevalência estimada de $40-50 \%$ (17). Sendo uma das principais complicações que aparece com o tempo de evolução do diabetes mellitus, é caracterizada pela degeneração progressiva dos axônios das fibras nervosas (17).

Por mecanismos ainda não bem elucidados, a hiperglicemia, presente especialmente em pacientes diabéticos não controlados, levaria a um aumento de diacilglicerol (logo, de proteino-cinase $\mathrm{C}$ ), aumento da lipoproteína de baixa densidade, e afetaria a via dos polióis, a autoxidação do açúcar e os produtos finais da glicação avançada, causaria também depleção de mioinositol nos nervos por um mecanismo de captação; tudo isso corroboraria para o estresse oxidativo, o que geraria uma disfunção endotelial, diminuindo o fluxo sanguíneo dos capilares, o que gera hipóxia endoneural. Todo esse contexto propicia um aumento do dano ou disfunção dos nervos, e concomitantemente leva a uma diminuição da capacidade de regeneração ou reparo desses nervos (19). Uma característica importante na neuropatia diabética é a presença de microangiopatia endoneural que se apresenta paralelamente à perda das fibras nervosas.

Recentemente, tem sido demonstrado que fibras pequenas são preferencialmente afetadas em estágios precoces em pacientes diabéticos, seguidos do posterior envolvimento de fibras largas, relacionadas com a velocidade de condução reduzida ou com o decréscimo do limiar de vibração. Os sinais e sintomas são baseados nas alterações estruturais. Quando as fibras nervosas que estão em degeneração ou regeneração debilitada produzem impulsos excitatórios, induzem sintomas subjetivos como a dor e a parestesia (sintomas positivos). Quando as fibras são perdidas, a perda da sensação será predominante. Com o aumento da perda das fibras, a área de perda de sensibilidade aumentará severamente (sintomas negativos) (17).

O exame clínico é atualmente considerado o padrão ouro para avaliação da neuropatia diabética e inclui tanto a obtenção de uma história clínica completa como 
um exame detalhado dos pés com a avaliação das sensibilidades dolorosa, vibratória, tátil e reflexo aquileu. Um método comumente empregado para avaliação da neuropatia diabética é o monofilamento (18).

A cartilagem articular é uma das estruturas que recebe a maior força compressiva e o maior choque mecânico entre todos os tecidos conjuntivos do corpo humano. O comprometimento axonal interfere com a percepção do impacto, especialmente nos membros inferiores. $O$ aumento do estresse mecânico aumenta a atividade de síntese dos condrócitos da cartilagem. A perda da proporção correta entre o poder de resistência do tecido e a demanda da carga do movimento altera o comportamento da cartilagem articular no manuseio das forças compressivas e tensionais. Assim, não somente se tem a dor neuropática, mas também a dor inflamatória e degenerativa (18).

Além de envolver fibras aferentes, a progressão da neuropatia pode desencadear um comprometimento de fibras nervosas motoras. Isso pode levar ao atraso de ativação de alguns músculos durante a marcha, o que, juntamente com o aparecimento de áreas anômalas de pressão na planta dos pés, causa uma perda gradual da estabilidade e do equilíbrio (20) O déficit sensitivo contribui nesse mecanismo, além de poder ocasionar deformidades osteoarticulares da região, que agravam o quadro (21).

Para manter a estabilidade postural e o equilíbrio, os sistemas vestibular, da visão e das informações táteis e proprioceptivas devem funcionar de forma integrada e coordenada (21). A sensibilidade plantar envia para o cérebro as informações a respeito de mudanças de pressão sobre o pé, principalmente durante a marcha, sendo essencial na geração de reflexos posturais. Um déficit nessa sensibilidade pode decorrer da neuropatia diabética e prejudicar o equilíbrio estático e dinâmico. Sales, Souza e Cardoso (21) compararam diabéticos neuropatas, diabéticos não neuropatas e indivíduos não diabéticos em relação ao seu equilíbrio estático e concluíram que a neuropatia influencia negativamente na manutenção deste. Outro estudo, de Brown et al (7), demonstrou ainda que existe uma maior separação do centro de massa em relação ao centro de pressão nestes pacientes, o que gera maior desafio para equilibrarem-se.

Uma das principais consequências desta instabilidade postural nos diabéticos neuropatas é o aumento do risco de quedas. Este risco aumenta ainda mais em mulheres, pela associação com outros fatores de risco (12). A definição de queda da 
Sociedade Brasileira de Geriatria e Gerontologia é: "o deslocamento não intencional do corpo para um nível inferior à posição inicial com incapacidade de correção em tempo hábil, determinado por circunstâncias multifatoriais comprometendo a estabilidade" (13).

Um estudo realizado em um Centro de Diabetes no Reino Unido analisou 66 pacientes com diabetes mellitus, dos quais 35\% respondeu que tinha sofrido uma queda no último ano. Os pesquisadores dividiram então a amostra em dois grupos: um que caiu no último ano e um que não caiu, e constataram uma incidência de neuropatia periférica maior no primeiro do que no segundo (86\% e 56\%, respectivamente). Verificaram também que os que caíram tinham menos força nos músculos dorsiflexores do tornozelo e marcha mais lenta, sugerindo que simples medições clínicas como estas poderiam identificar os pacientes em maior risco e servir como estratégia de prevenção para queda na população diabética (13).

Em uma cidade de médio porte no sul do país, realizaram um estudo (22) que obteve resultados semelhantes. Comparando o risco de queda em pacientes com e sem diabetes mellitus tipo 2, concluíram que o prejuízo na mobilidade funcional é maior entre os pacientes diabéticos e que esse conhecimento permite traçar estratégias de prevenção na rede pública de saúde.

A literatura demonstra ainda que os pacientes neuropatas dependem enormemente de informações visuais como estratégia de controle postural (8). Porém, sabe-se que muitos diabéticos também apresentam retinopatias, podendo prejudicar ainda mais seu equilíbrio estático e dinâmico.

Wallace et al (15) estudaram 400 diabéticos e constataram uma prevalência de quedas que chega a 1,25 por ano. A maior propensão a quedas nos pacientes diabéticos afeta enormemente a sua qualidade de vida, pois pode resultar em fraturas, diminuição da autonomia, declínio da mobilidade, evitação de atividades, hospitalização e maior morbimortalidade $(7,10)$.

A consequência mais grave das quedas são as fraturas. Em 40 a $60 \%$ dos episódios de queda em idosos no Brasil ocorrem lesões, sendo 5\% delas fraturas (13). Existem evidências de que a população diabética está mais propensa a sofrer essa complicação, devido a uma maior fragilidade óssea que ocorre na diabetes mellitus, principalmente do tipo 2. Esta alteração parece ser independente da densidade 
mineral óssea e mais associada ao aumento da porosidade cortical, a um prejuízo na arquitetura óssea e à redução na taxa de renovação óssea. Logo, entende-se que existe aumento no risco de fratura na diabetes, devido tanto a uma maior frequência de quedas quanto à menor resistência óssea. Uma recente revisão de literatura a respeito do metabolismo ósseo no diabetes explica essa fisiopatologia (18).

A hiperglicemia afeta a matriz óssea devido ao acúmulo de produtos finais de glicação avançada (AGEs) e ao aumento de diferenciação de osteoclastos. Os AGEs, principalmente a pentosidina, dificultam a capacidade do osso de se deformar antes de fraturar.

A insulina é um hormônio anabólico que atua sobre o tecido ósseo principalmente através de receptores nos osteoblastos e sua diminuição na diabetes pode provocar fragilidade óssea. Além disso, esse hormônio estimula a osteocalcina, importante marcador de formação óssea, que se encontra reduzido nos pacientes diabéticos. Pelo contrário, marcadores osteocíticos, principalmente a esclerositina, estão aumentados nesses pacientes, em associação com o tempo e o controle da doença.

Adicionalmente, sabe-se que o diabetes mellitus é uma importante causa de doença renal crônica, a qual predispõe a um baixo estado de remodelação óssea, a osteodistrofia renal. Um melhor controle glicêmico reduziria enormemente todo este quadro além de retardar outras complicações da doença, como a neuropatia e a retinopatia, aliviando, por consequência, o risco de quedas e de fraturas. No entanto, é importante que esses pacientes sejam vistos como população de risco e também se previnam de outras formas: redução no tabagismo, sedentarismo e deficiência de vitamina $D$.

\section{METODOLOGIA}

O projeto foi realizado por meio de análise de dados clínicos e exame físico de pacientes com DM2 que fazem acompanhamento no Centro de Saúde Número 9 da Secretaria de Saúde do Distrito Federal (SES-DF), localizado no bairro Cruzeiro Novo.

Após a aprovação pelo Comitê de Ética e Pesquisa da Secretaria de Saúde do DF pelo parecer número 1.851.206, foi iniciada a coleta de dados e avaliação clínica dos pacientes atendidos no Centro de Saúde. Todos os pacientes registrados no livro do grupo de diabetes existente no Centro de Saúde que cumpriam os critérios de 
inclusão da nossa pesquisa foram selecionados. Os pré-requisitos para ser incluso no trabalho eram possuir o diagnóstico de DM2 e ter entre 50 e 70 anos. Foram excluídos dessa avaliação os pacientes que apresentavam outras causas para a neuropatia como as seguintes listadas: insuficiência renal, hipotireoidismo descompensado, história de etilismo, tabagismo, deficiência de ácido fólico, síndromes paraneoplásicas, uso de antidepressivos ou sedativos, ou ainda, concomitância de outros sintomas neurológicos ainda em investigação que se encaixam em outras síndromes neurológicas.

Os pacientes selecionados foram contatados por telefone e questionados sobre o desejo de colaborar com sua participação no trabalho e esclarecidos sobre o mesmo. Quando aceitavam, era marcado um horário para que comparecessem ao Centro de Saúde. Neste momento, solicitava-se que o paciente fizesse a leitura do termo de consentimento livre e esclarecido- TCLE (ANEXO A) antes de iniciar a entrevista, assinando o TCLE caso concordasse com a participação. Cada paciente foi submetido a um questionário inicial (APÊNDICE A) e também foram coletados dados dos prontuários eletrônicos dos que tinham os itens necessários disponíveis.

No questionário continha dados como idade, sexo, grau de escolaridade, profissão, estimativa da renda familiar, número de pessoas residentes na mesma moradia e tipo de moradia, presença ou não de tabagismo e realização ou não de atividades físicas regulares (pelo menos 150 minutos por semana). Também foram questionadas características da doença como: data do diagnóstico do DM2, medicações já utilizadas previamente, quais as medicações utilizadas atualmente, sintomas que podem sugerir mau controle (poliúria, polidipsia, emagrecimento). Também no questionário foram incluídas questões sobre a presença de quedas com e sem fraturas do paciente em questão no ano anterior a sua avaliação.

Após a realização do questionário, o participante foi submetido ao exame detalhado de membros inferiores, sendo realizada a avaliação da sensibilidade sensitiva pelo teste de monofilamento, bem como avaliação das sensibilidades tátil, dolorosa, vibratória e térmica e do reflexo aquileu (23). Então, o paciente foi submetido a um teste já padronizado para screening de neuropatia diabética sensitivomotora periférica denominado "United Kingdom Screening Test" (QUADRO 1) que permite identificar presença ou ausência de neuropatia, assim como classificá-la. Esse teste 
é dividido em duas partes que consistem em uma avaliação dos sintomas apresentados pelo paciente e exame físico (24). Cada paciente recebeu uma pontuação de acordo com sua avaliação entre 0 e 10, sendo considerada neuropatia periférica na existência de sinais moderados ou graves ( $\geq 6$ pontos); se há pelo menos sinais leves, mesmo na ausência de sintomas ( $\geq 3$ pontos); ou na presença de sintomas moderados ( $\geq 5$ pontos). A pontuação maior que oito indica um alto risco de ulceração.

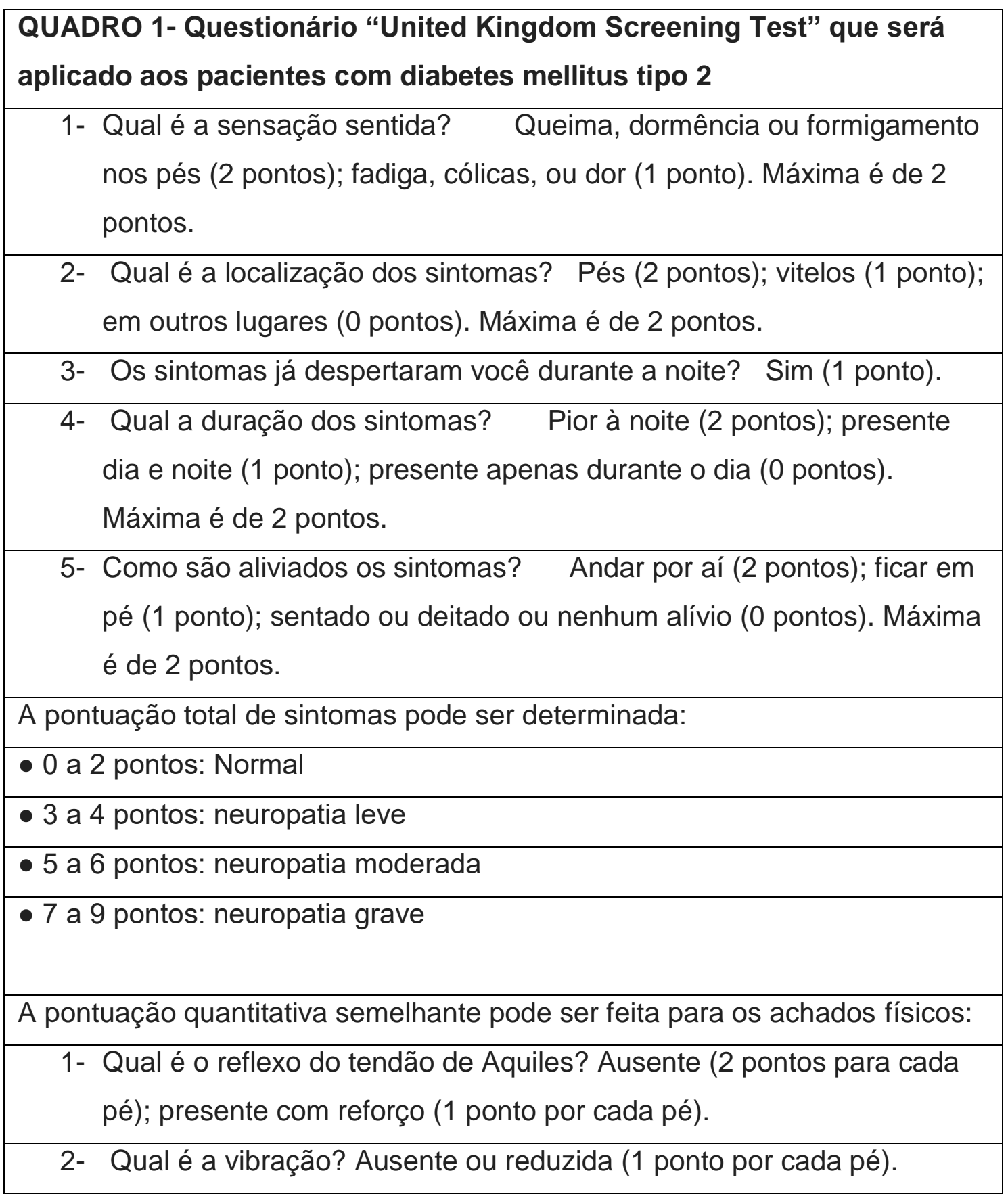


3- Qual é a sensação da agulha? Ausente ou reduzida (1 ponto por cada pé).

4- Qual é a sensação de temperatura? Reduzida (1 ponto por cada pé).

A pontuação total dos sinais neurológicos pode então ser determinada:

- 0 a 2 pontos: Normal

- 3 a 5 pontos: neuropatia leve

- 6 a 8 pontos: neuropatia moderada

- 9 a 10 pontos: neuropatia grave

Após isso, foi realizada a avaliação do equilíbrio estático e dinâmico. O teste padrão-ouro para essa avaliação é o teste "Berg and Balance Scale" (BSS) que consiste de um válido instrumento já utilizado para a avaliação da eficácia das intervenções na prática clínica e na pesquisa. Ele consiste em uma escala de 14 itens que incluem a realização de simples tarefas de equilíbrio, alterações posturais e posições, transferências e manobras de recuperação de objetos simples. A capacidade de executar cada tarefa é avaliada com uma pontuação de 0 (incapaz) a 4 (independente) e o resultado final é a soma de todas as pontuações; quanto menor a pontuação mais grave é o prejuízo no equilíbrio estático e dinâmico $(25,26)$ (ANEXO B).

Também foi feita a avaliação da mobilidade funcional através do teste TUG, um teste válido e confiável, que também pode ser útil na avaliação clínica ao longo do tempo. É cronometrado o intervalo de tempo que o paciente requer para se levantar de uma de uma poltrona, caminhar 3 metros, andar para trás, e sentar-se novamente. O comprometimento do equilíbrio estático e do equilíbrio dinâmico se traduzem em uma maior duração necessária para realizar as tarefas do teste. (27)

Após a coleta desses dados, foi feita uma análise das características sociais e clínicas mais comuns dos participantes, para verificar se alguma delas possui um valor preditivo para desenvolvimento de neuropatia diabética e para maior risco de quedas. Além disso, foi analisada a presença de correlação entre o grau de neuropatia apresentado pelos pacientes e o risco de quedas estimado pelos testes acima, assim como com a ocorrência de quedas no período do ano anterior e dois meses após a avaliação dos mesmos. 
Os dados coletados foram analisados utilizando os softwares: SPSS v17 (SPSS Inc, Chicago, IL, EUA) e R (version 3.3.3). Os resultados obtidos foram comparados aos já publicados na literatura. Dados contínuos foram expressos por valores de mediana (do mínimo ao máximo). Diferenças entre dois grupos foram analisadas por meio do teste Mann-Whitney $U$ de cauda dupla. $O$ teste exato de Fisher ou o teste do $x 2$ foi utilizado para investigação de variáveis dicotômicas. Os intervalos de confiança 95\% (IC 95\%) em análises univariadas e multivariadas de $p<0,05$ foram considerados significativo.

\section{RESULTADOS E DISCUSSÃO}

A amostra analisada foi composta no total por 60 pacientes diabéticos tipo 2 que faziam acompanhamento clínico no Centro de Saúde número 9 do Distrito Federal, entretanto, dentre esses, apenas 40 se adequaram aos critérios de inclusão da pesquisa. A maioria desses pacientes (72,5\%) era do sexo feminino. A idade média dos pacientes da amostra foi de 62 anos, dado compatível com o critério de inclusão da pesquisa (ter idade entre 50 e 70 anos). A pesquisa foi realizada em um Centro de Saúde do SUS localizado na região administrativa do Cruzeiro Novo, a qual abriga uma população com renda média mensal de $R \$ 3.155,00$ (dados da Codeplan de $2004)^{* 2}$. A renda familiar média dos pacientes participantes da pesquisa foi de aproximadamente 7 salários mínimos (SM), o que pode ser considerada uma renda alta comparada a média da população da região, apesar de se tratar de um serviço de saúde pública. Além disso, $84,35 \%$ possuíam pelo menos o ensino médio completo e $43,75 \%$ dos entrevistados possuíam ensino superior completo (TABELAS 1 e 2 ).

\footnotetext{
*2 Disponível em: http://www.anuariododf.com.br/regioes-administrativas/ra-xi-cruzeiro/
} 
Tabela 1 - Informações dos indivíduos pesquisados

\begin{tabular}{l|r|r}
\hline \multicolumn{1}{c|}{ Variável } & \multicolumn{1}{c|}{ Média } & \multicolumn{2}{c}{$\begin{array}{c}\text { Desvio } \\
\text { padrão }\end{array}$} \\
\hline ldade & 62,3 & 4,4 \\
\hline $\begin{array}{l}\text { Renda familiar (em Salários } \\
\text { Mínimos) }\end{array}$ & 6,8 & 5,8 \\
\hline $\begin{array}{l}\text { Pessoas residentes na } \\
\text { moradia }\end{array}$ & 2,9 & 1,4 \\
\hline
\end{tabular}

Tabela 2 - Caracterização dos indivíduos pesquisados

\begin{tabular}{c|l|r|r}
\hline Variável & \multicolumn{1}{|c|}{ Categoria } & Qtd & \multicolumn{1}{c}{$\%$} \\
\hline \multirow{4}{*}{ Sexo } & Feminino & 29 & 72,5 \\
& Masculino & 11 & 27,5 \\
& Total & 40 & 100,0 \\
\hline \multirow{5}{*}{ Escolaridade } & Fundamental incompleto & 8 & 25,0 \\
& Fundamental completo & 3 & 9,4 \\
& Médio incompleto & 2 & 6,3 \\
& Médio completo & 13 & 40,6 \\
& Ensino Superior & 14 & 43,75 \\
& Superior completo & 10 & 31,3 \\
& Superior incompleto & 3 & 9,4 \\
& Pós-graduação & 1 & 3,1 \\
& Total & 32 & 100,0 \\
\hline
\end{tabular}

Com relação aos hábitos de vida dos indivíduos pesquisados, houve uma prevalência semelhante quanto ao hábito do tabagismo, ou seja, 52,5\% nunca fumaram e 47,5\% apresentam ou apresentaram contato com fumo alguma vez na vida (soma de tabagistas e ex- tabagistas). Cerca de $70 \%$ dos pacientes praticavam alguma atividade física regular (150 minutos por semana), sendo que essa variável 
pode ser decorrente de os participantes frequentarem um grupo no centro de saúde que estimula a prática de exercícios físicos.

Em relação à hipertensão arterial sistêmica (HAS), 77,5\% apresentaram esse diagnóstico. Portanto, houve uma forte associação entre a DM2 e HAS. Este dado converge com o que é apresentado na literatura. De acordo com o Ministério da Saúde, a possibilidade de associação das duas doenças é de cerca de $50 \%$. A presença destas comorbidades confere um maior risco cardiovascular. (28)

Dos pacientes avaliados, a maior parte $(57,5 \%)$ apresentou índice de massa corporal (IMC) maior do que 30, podendo ser classificados como obesos. Apenas 10\% dos entrevistados apresentaram um IMC normal e $32,5 \%$ possui um IMC correspondente a sobrepeso.

O Gráfico 1 mostra o perfil dos medicamentos utilizados para o tratamento do DM2 na população estudada. Verifica-se a predominância do uso da Metformina em $80 \%$ dos pesquisados, seguido da utilização de Gliclazida em $40 \%$ dos casos. No mais, dentre os tipos de insulina utilizada, houve maior prevalência da NPH (Neutral Protamine de Hagedorn), usada por 32,5\% dos indivíduos pesquisados. Esse dado pode ser consequência da aplicação das recomendações para tratamento do DM2 que preconiza a metformina como medicação inicial a ser utilizada no tratamento, ou ainda, pode guardar relação com o fato de a medicação ser de fácil acesso, disponível gratuitamente na rede pública para os usuários. A gliclazida e a insulina NPH também são medicamentos disponibilizados gratuitamente pela SES-DF, o que justifica a preferência quase absoluta por essas três medicações e pelas associações entre elas.

Apenas pequena porcentagem dos pacientes utilizava medicamentos como Linagliptina (5\%), Sitagliptina $(7,5 \%)$ e Vildagliptina (5\%), possivelmente por se tratarem de medicações de alto custo e não fornecidas gratuitamente pelo SUS, além de geralmente não serem consideradas como medida inicial no tratamento da DM2.

\section{Gráfico 1 - Medicamentos utilizados para tratamento de Diabetes Mellitus}




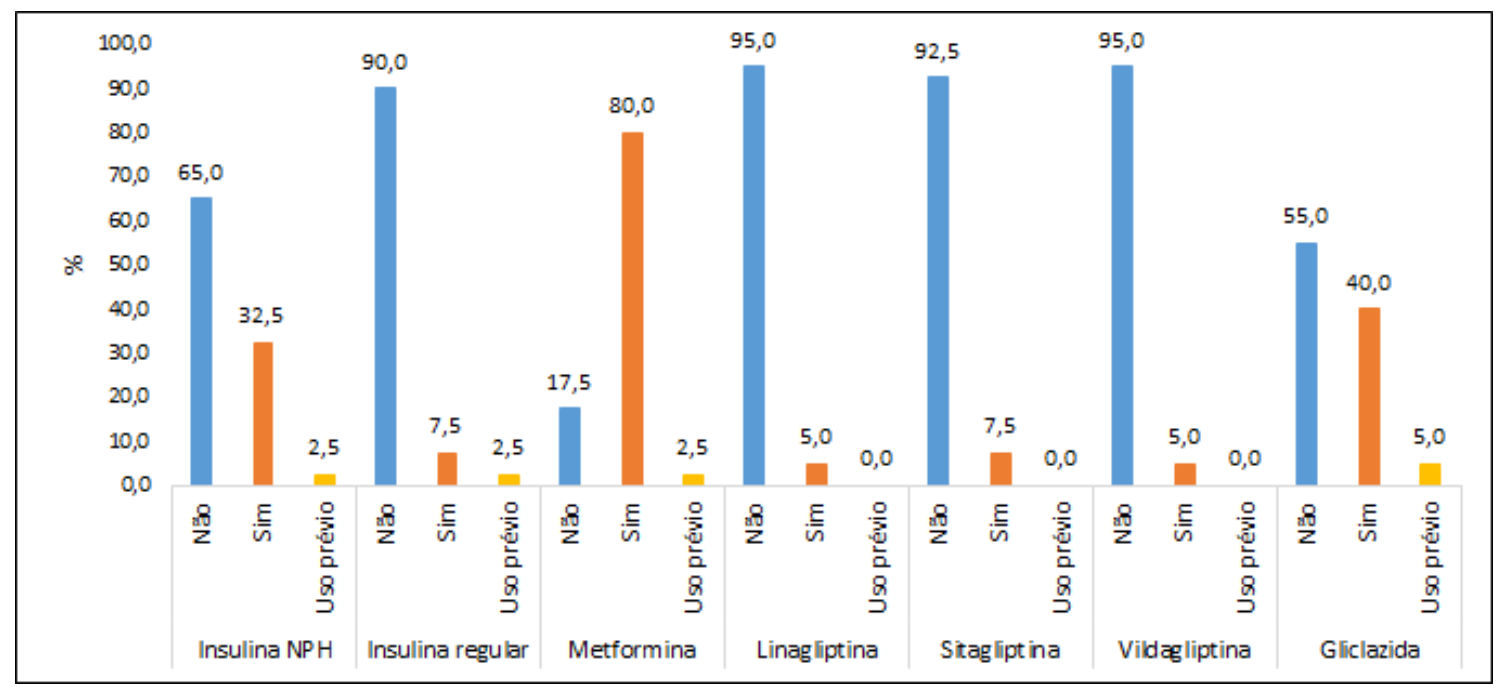

Dentre 40 pacientes da pesquisa avaliados pelo "United Kingdom Screening Test", 16 pacientes possuiam diagnóstico de neuropatia, sendo que 43,75\%, grau leve, $37,5 \%$ moderado e $18,75 \%$ grave. Os outros 24 participantes foram classificados como normais, ou seja, não possuem nenhum grau de neuropatia, representando $60 \%$ da nossa amostra.

Gráfico 2 - Classificação dos pacientes segundo o questionário "United Kingdom Screening Test"

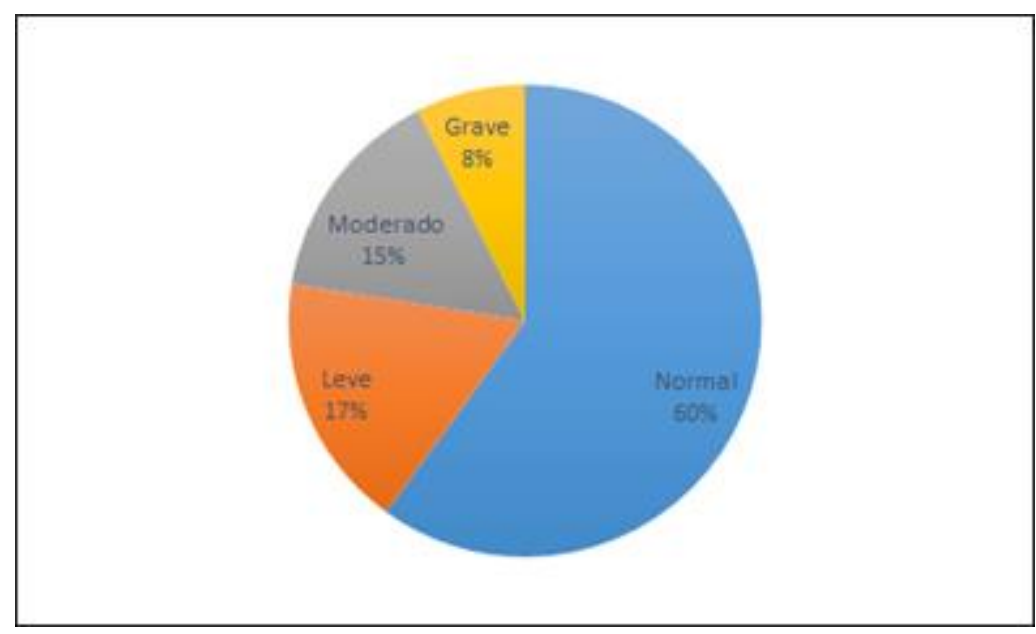

Dos 16 que apresentaram qualquer grau de neuropatia por este teste, $60 \%$ havia sofrido queda no ano anterior, com um p-valor sugerindo uma tendência a significância da relação $(0,1003)$. Como o tamanho da amostra era pequeno, é possível ponderar que essa poderia ser uma justificativa para tal fato. Desses pacientes com neuropatia 
que apresentaram quedas, $40 \%$ apresentavam sintomas de neuropatia moderada pelo "United Kingdom Screening Test".

Foi realizada uma análise comparativa entre o grupo de indivíduos que relataram ter sofrido algum tipo de queda no ano anterior, composto por 10 indivíduos (25\% da amostra), e o grupo dos que não sofreram queda, composto por 30 indivíduos pesquisados (75\% da amostra). Dos que haviam sofrido queda no ano anterior, $70 \%$ possuíam diagnóstico de neuropatia de acordo com o "United Kingdom Screening Test”. Já no grupo que não sofreu queda, este diagnóstico esteve presente em 40\% dos casos. O p-valor desta relação ainda não é altamente significativo ( $p=0,1482)$, porém chama a atenção. É possível que houvesse maior significância caso o tamanho da amostra fosse maior. É uma relação para se testar futuramente com um $n$ maior.

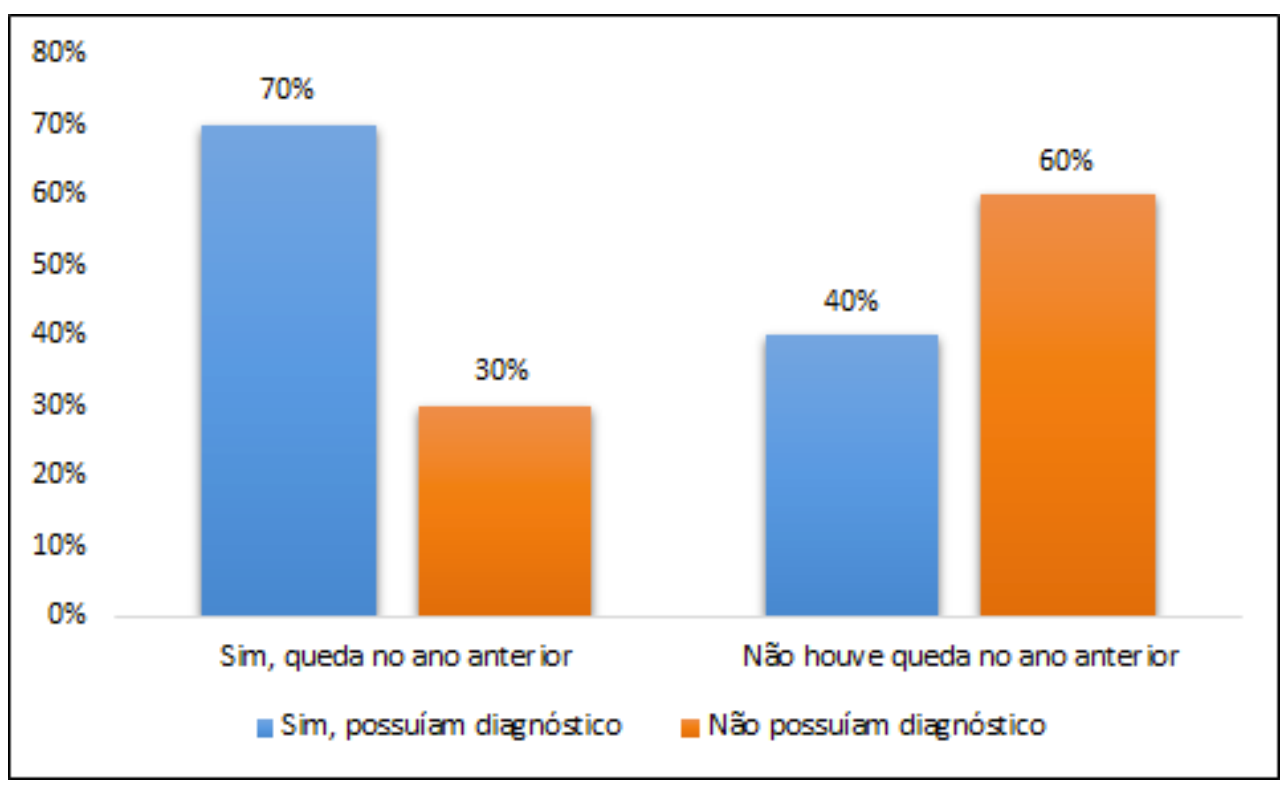

Um estudo realizado em um Centro de Diabetes no Reino Unido, que analisou 66 pacientes com diabetes mellitus, obteve resultados semelhantes. Neste estudo, $35 \%$ dos entrevistados tinha sofrido queda no último ano e foi constada uma incidência de neuropatia periférica maior no grupo que teve queda do que no que não teve ( $86 \%$ e $56 \%$, respectivamente) (13).

No grupo de pacientes que não sofreram queda no ano anterior, o tempo médio de diagnóstico foi de 10,7 anos, porém quanto ao grupo com queda, o tempo foi de 
16,4 anos. A diferença de 5,7 anos pode sugerir que quanto maior o tempo de doença maior a ocorrência de quedas, porém relação não foi significativa $(p=0,233)$.

A média de renda familiar do grupo de indivíduos que não tiveram queda no ano anterior era de 7,4 SM enquanto que a dos que tiveram queda era inferior a 5,2 SM, diferença que não foi estatisticamente significativa (TABELA 3).

Tabela 3 - Informações socioeconômicas segundo presença de queda no ano anterior

\begin{tabular}{l|r|r|c}
\hline \multirow{2}{*}{ Variáveis } & \multicolumn{2}{|c|}{$\begin{array}{c}\text { Presença quedas } \\
\text { no ano anterior? }\end{array}$} & \multirow{2}{*}{ p-valor } \\
\cline { 2 - 3 } & \multicolumn{1}{c|}{ Não } & \multicolumn{1}{c|}{ Sim } & \\
\hline Idade & 62,8 & 60,8 & 0,1771 \\
\hline $\begin{array}{l}\text { Renda familiar (salários } \\
\text { mínimos) }\end{array}$ & 7,4 & 5,2 & \multirow{2}{*}{0,481} \\
\hline $\begin{array}{l}\text { Pessoas residentes na } \\
\text { moradia }\end{array}$ & 3,1 & 2,4 & 0,286 \\
\hline
\end{tabular}

Além disso, verifica-se que $63,3 \%$ dos que não apresentaram queda no ano anterior nunca fumaram, porém, ao analisar o grupo dos que apresentaram queda, $70 \%$ afirmaram ser tabagistas. O p-valor de 0,025 mostra que essa diferença é significativa para o grupo pesquisado. Isso indica uma possível associação entre o hábito de fumar e o risco aumentado de quedas (TABELA 4).

Não houve diferença no número de quedas entre os pacientes que realizavam atividade física e os que não realizavam. Com relação às comorbidades apresentadas, a prevalência de HAS e dislipidemia foram semelhantes entre o grupo de pacientes que apresentou queda e o grupo que não apresentou queda no ano anterior à avaliação (TABELA 4).

Tabela 4 - Informações de antecedentes segundo presença de queda no ano anterior 


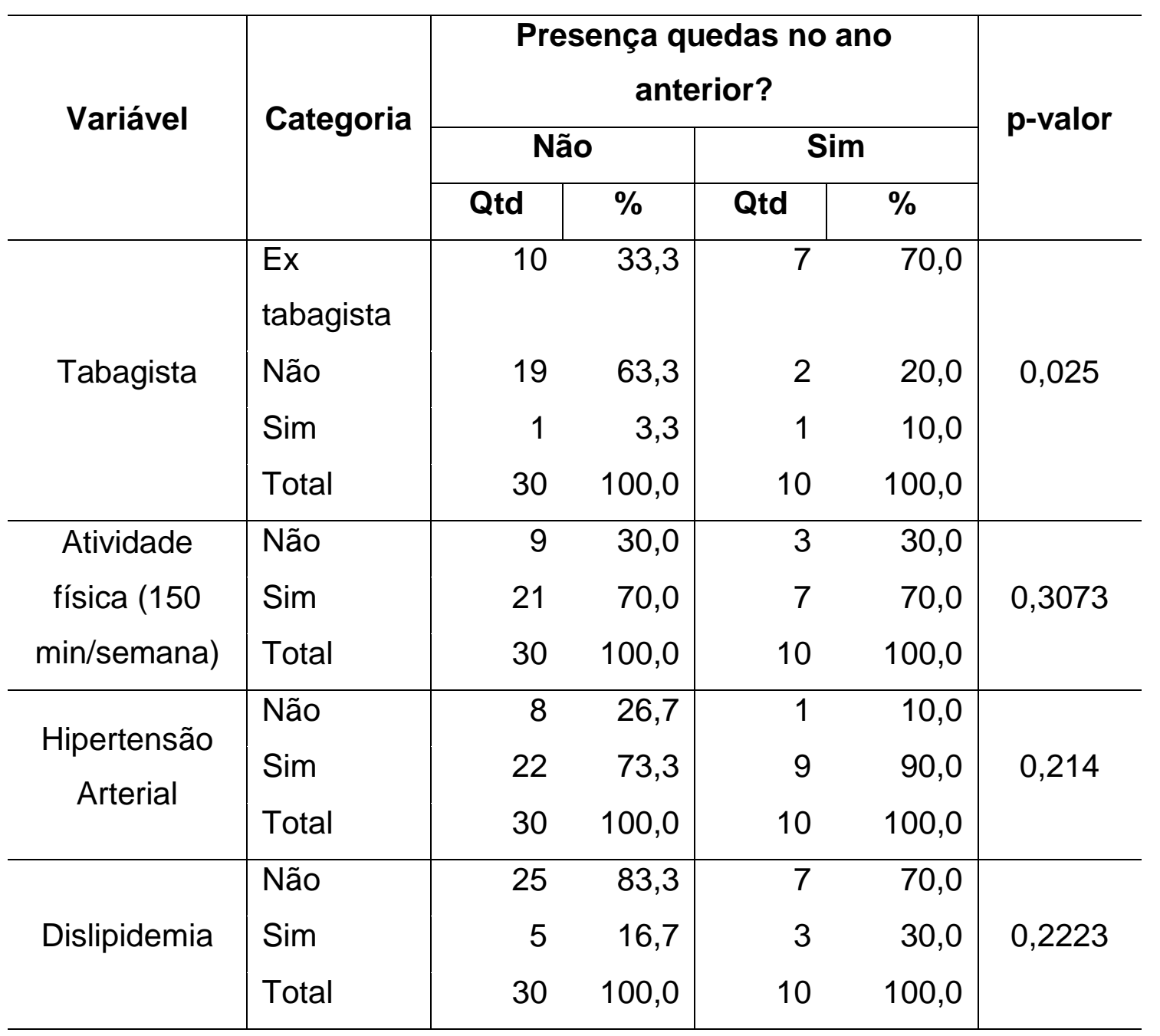

Durante a realização do trabalho foram coletados dados acerca do nível de controle glicêmico dos pacientes, sendo observados os seguintes itens: glicemia de jejum, glicemia pós-prandial e hemoglobina glicada. A glicemia de jejum pôde ser avaliada em 38 pacientes, a glicemia pós-prandial em 14 e a hemoglobina glicada em 12 pacientes. Quanto ao controle glicêmico, não houve diferença estatística entre os níveis de glicemia de jejum e de glicemia pós-prandial entre o grupo que apresentou queda e o que não apresentou queda no ano anterior (TABELA 5). A pouca quantidade de pacientes que apresentavam os dois últimos parâmetros foi consequente à não aferição da glicemia pós-prandial pelo paciente e pelos resultados da hemoglobina glicada não constarem no sistema (TrackCare) ou pela não realização deste exame para controle glicêmico, provavelmente influenciando nos $p$-valores obtidos, sendo que este sugere que não houve diferenças médias significativas a $5 \%$. 
Tabela 5 - Informações de Comorbidades e Controle glicêmico, segundo presença de queda no ano anterior

\begin{tabular}{|c|c|c|c|c|c|c|c|c|}
\hline \multirow{3}{*}{ Variáveis } & \multirow{3}{*}{ Categorias } & \multicolumn{4}{|c|}{$\begin{array}{c}\text { Houve quedas no ano } \\
\text { anterior? }\end{array}$} & \multirow{2}{*}{\multicolumn{2}{|c|}{ Total }} & \multirow{3}{*}{$\begin{array}{c}p- \\
\text { valor }\end{array}$} \\
\hline & & \multicolumn{2}{|c|}{ Não } & \multicolumn{2}{|c|}{ Sim } & & & \\
\hline & & Qtd & $\%$ & Qtd & $\%$ & Qtd & $\%$ & \\
\hline \multirow{3}{*}{$\begin{array}{l}\text { Neuropatia } \\
\text { sintoma }\end{array}$} & Normal & 20 & 66,7 & 4 & 40,0 & 24 & 60,0 & \multirow{3}{*}{0,1003} \\
\hline & $\begin{array}{l}\text { Algum nível de } \\
\text { neuropatia }\end{array}$ & 10 & 33,3 & 6 & 60,0 & 16 & 40,0 & \\
\hline & Total & 30 & 100,0 & 10 & 100,0 & 40 & 100,0 & \\
\hline \multirow{3}{*}{$\begin{array}{l}\text { Neuropatia } \\
\text { sinais }\end{array}$} & Normal & 28 & 93,3 & 8 & 80,0 & 36 & 90,0 & \multirow{3}{*}{0,2142} \\
\hline & $\begin{array}{l}\text { Algum nível de } \\
\text { neuropatia }\end{array}$ & 2 & 6,7 & 2 & 20,0 & 4 & 10,0 & \\
\hline & Total & 30 & 100,0 & 10 & 100,0 & 40 & 100,0 & \\
\hline \multirow{3}{*}{$\begin{array}{l}\text { Glicemia de } \\
\text { Jejum (GJ) }\end{array}$} & GJ $<99$ & 7 & 25,0 & 4 & 40,0 & 11 & 28,9 & \multirow{3}{*}{0,2066} \\
\hline & GJ > $>99$ & 21 & 75,0 & 6 & 60,0 & 27 & 71,1 & \\
\hline & Total & 28 & 100,0 & 10 & 100,0 & 38 & 100,0 & \\
\hline Glicemia pós & GPP $<140$ & 4 & 36,4 & 0 & 0,0 & 4 & 28,6 & \\
\hline prandial & GPP $<=140$ & 7 & 63,6 & 3 & 100,0 & 10 & 71,4 & 0,4396 \\
\hline (GPP) & Total & 11 & 100,0 & 3 & 100,0 & 14 & 100,0 & \\
\hline
\end{tabular}

A diferença de glicemia de jejum entre os que sofreram e que não sofreram queda no ano anterior foi de 13,8 mg/dl, o p-valor de 0,961 informa que esta diferença não é significativa. O mesmo ocorre ao analisar a circunferência abdominal entre os grupos pesquisados que gerou um p-valor de 0,7941, inferindo que a diferença de 4,6 cm $(102,5 \mathrm{~cm}-97,9 \mathrm{~cm})$ não é significativa.

Dentre o grupo que não sofreu queda, 90\% usam Metformina no seu tratamento. Já o grupo que apresentou queda, apenas $60 \%$ deles utilizou tal medicamento. $O p$-valor de 0,0457 sugere que esta relação foi significativa para os indivíduos pesquisados. $\mathrm{O}$ uso da Metformina associado à não ocorrência de quedas reforça a ideia de que um controle glicêmico adequado poderia reduzir as quedas devido a DM ou mesmo à neuropatia diabética. 
Em nova análise 4 meses após a aplicação dos questionários e testes, foi constatado que $40 \%$ dos que haviam sofrido algum tipo de queda nesse período, possuíam algum nível de neuropatia. Isso também reforça que pode existir associação de quedas com diagnóstico de neuropatia.

Com relação aos testes de equilíbrio (TUG e TEFB) e a presença de quedas verificada após aproximadamente 4 meses da aplicação do questionário, pode-se constatar que o teste TUG aparenta ser melhor preditor da ocorrência de quedas.

Tabela 6 - Médias de testes utilizados na pesquisa segundo existência de queda

\begin{tabular}{r|r|r|r}
\hline \multirow{2}{*}{$\begin{array}{c}\text { Tipo } \\
\text { de teste }\end{array}$} & \multicolumn{2}{|c|}{ Sofreu queda? } & \multirow{2}{*}{ p-valor } \\
\cline { 2 - 3 } & Não & Sim & \\
\hline TUG & 14,34 & 15,30 & 0,501 \\
\hline TEFB & 54,3 & 54,2 & 0,911 \\
\hline
\end{tabular}

Dentre os pacientes que tiveram queda no ano anterior à aplicação do questionário, nenhum deles sofreu nenhum tipo de fratura. Como apenas um paciente havia sofrido fratura na análise após 4 meses da aplicação do questionário, não foi possível avaliar informações acerca das quedas com fraturas para o "n" estudado. Sabe-se que pacientes com DM possuem um risco aumentado de fraturas, já que há uma redução de insulina (a qual é um hormônio anabólico que atua sobre o tecido ósseo), provocando fragilidade óssea, entretanto não pôde ser constatado nessa amostra. Alguns fatores que podem ter influenciado nesse resultado são: o pequeno número de pacientes da amostra e o fato de esses serem pacientes com acompanhamento regular participantes de um grupo que auxilia nas orientações e cuidados preventivos ao paciente diabético. 


\section{CONSIDERAÇÕES FINAIS}

Este trabalho buscou avaliar a existência de correlação entre a presença de neuropatia diabética e um risco aumentado para a ocorrência de quedas com e sem fraturas em um grupo de 40 diabéticos acompanhados em um Centro de Saúde do DF. A amostra analisada constituía-se em sua maioria pelo sexo feminino, com média de idade de 62 anos e renda familiar média de sete salários mínimos, e a maior parte tinha no mínimo ensino médio completo. $70 \%$ dos pacientes praticavam exercício físico regularmente (150 $\mathrm{min} / \mathrm{semana})$. Corroborando com a associação entre DM e hipertensão arterial, $77,5 \%$ dos indivíduos pesquisados apresentou essa comorbidade. No geral, os pacientes apresentaram IMC maior que 30 , caracterizando obesidade. Houve predominância do uso de metformina na amostra (80\%).

Com relação à neuropatia, 16 pacientes enquadravam-se neste diagnóstico, sendo que, destes, $43,75 \%$ eram de grau leve, $37,5 \%$ moderado e $18,75 \%$ grave. Os outros 24 participantes não apresentaram nenhum grau de neuropatia, representando $60 \%$ da amostra.

Quanto ao controle glicêmico, não houve diferença estatística entre os níveis de glicemia de jejum e de glicemia pós-prandial entre o grupo que apresentou queda e o que não apresentou queda no ano anterior. Este resultado provavelmente foi influenciado pela pouca quantidade de pacientes que tinham os dois últimos parâmetros disponíveis para análise devido à não realização do exame ou ao resultado não constar no sistema.

Foi constatado que $60 \%$ dos participantes com algum grau de neuropatia de acordo com o "United Kingdom Screening Test" haviam sofrido queda no ano anterior $(p=0,1003)$ à avalição. Esse dado tendeu a significância, porém pode ter sido limitado pelo tamanho da amostra. Foi realizada, ainda, uma análise comparativa entre o grupo de indivíduos que relataram ter sofrido algum tipo de queda no ano anterior (25\% da amostra) e o grupo dos que não sofreram queda ( $75 \%$ da amostra). Dos que haviam sofrido queda no ano anterior, $70 \%$ possuíam diagnóstico de neuropatia de acordo com o "United Kingdom Screening Test". Já no grupo que não sofreu queda, este diagnóstico esteve presente em $40 \%$ dos casos. O p-valor desta relação ainda não é altamente significativo $(p=0,1482)$, porém chama a atenção. É possível que houvesse 
maior significância caso o tamanho da amostra fosse maior. É uma relação para se testar futuramente com um $n$ maior.

É possível ainda questionar se poderiam ter sido gerados dados mais significativos em relação ao risco de quedas causado pela neuropatia caso mais pacientes com esse diagnóstico tivessem sido avaliados pelos testes de equilíbrio. Apesar de muitos pacientes terem explicitado bem seu sintomas durante a aplicação do questionário, há a possibilidade de eles não necessariamente terem compreendido as instruções para responder ao questionário adequadamente, mesmo com essas informações tendo sido fornecidas conforme sugestão dos autores deste método de avaliação. Sugerimos que outros estudos sejam realizados nesta direção, possivelmente com uma amostra que incluísse apenas pacientes diabéticos neuropatas.

\section{REFERÊNCIAS BIBLIOGRÁFICAS}

1. Guariguata L, Whiting DR, Hambleton I, Beagley J, Linnenkamp U, Shaw JE. Global estimates of diabetes prevalence for 2013 and projections for 2035. Diabetes Res Clin Pract2014 Feb;103(2):137-49.

2. Moraes SA, Freitas IC, Gimeno SG, Mondini L. [Diabetes mellitus prevalence and associated factors in adults in Ribeirao Preto, Sao Paulo, Brazil, 2006: OBEDIARP Project]. Cad Saude Publica2010 May;26(5):929-41.

3. Bansal V, Kalita J, Misra UK. Diabetic neuropathy. Postgrad Med J2006 Feb;82(964):95-100.

4. Dyck PJ, Kratz KM, Karnes JL, Litchy WJ, Klein R, Pach JM, et al. The prevalence by staged severity of various types of diabetic neuropathy, retinopathy, and nephropathy in a population-based cohort: the Rochester Diabetic Neuropathy Study. Neurology1993 Apr;43(4):817-24.

5. Franse LV, Valk GD, Dekker JH, Heine RJ, van Eijk JT. 'Numbness of the feet' is a poor indicator for polyneuropathy in Type 2 diabetic patients. Diabet Med2000 Feb;17(2):105-10.

6. Tesfaye S, Selvarajah D. Advances in the epidemiology, pathogenesis and management of diabetic peripheral neuropathy. Diabetes Metab Res Rev2012 Feb;28 Suppl 1:8-14.

7. Brown SJ, Handsaker JC, Bowling FL, Boulton AJ, Reeves ND. Diabetic peripheral neuropathy compromises balance during daily activities. Diabetes Care2015 Jun;38(6):1116-22. 
8. Chau RM, Ng TK, Kwan RL, Choi CH, Cheing GL. Risk of fall for people with diabetes. Disabil Rehabil2013;35(23):1975-80.

9. Bretan O. Plantar cutaneous sensitivity as a risk for falls in the elderly. Rev Assoc Med Bras2012 Mar-Apr;58(2):132.

10. Hewston P, Deshpande N. Falls and Balance Impairments in Older Adults with Type 2 Diabetes: Thinking Beyond Diabetic Peripheral Neuropathy. Can J Diabetes2015 Feb;40(1):6-9.

11. Timar B, Timar R, Gaita L, Oancea C, Levai C, Lungeanu D. The Impact of Diabetic Neuropathy on Balance and on the Risk of Falls in Patients with Type 2 Diabetes Mellitus: A Cross-Sectional Study. PLoS One2016;11(4):e0154654.

12. Schwartz AV, Hillier TA, Sellmeyer DE, Resnick HE, Gregg E, Ensrud KE, et al. Older women with diabetes have a higher risk of falls: a prospective study. Diabetes Care2002 Oct;25(10):1749-54.

13. Buskman S VA, Pereira SRM, Lino VS, Santos VH. Queda em Idosos: Prevenção. Sociedade Brasileira de Geriatria e Gerontologia2008.

14. Macgilchrist C, Paul L, Ellis BM, Howe TE, Kennon B, Godwin J. Lower-limb risk factors for falls in people with diabetes mellitus. Diabet Med2010 Feb;27(2):162-8.

15. Wallace C, Reiber GE, LeMaster J, Smith DG, Sullivan K, Hayes S, et al. Incidence of falls, risk factors for falls, and fall-related fractures in individuals with diabetes and a prior foot ulcer. Diabetes Care2002 Nov;25(11):1983-6.

16. Salkeld G, Cameron ID, Cumming RG, Easter S, Seymour J, Kurrle SE, et al. Quality of life related to fear of falling and hip fracture in older women: a time trade off study. BMJ2000 Feb 5;320(7231):341-6.

17. Yagihashi S, Yamagishi S, Wada R. Pathology and pathogenetic mechanisms of diabetic neuropathy: correlation with clinical signs and symptoms. Diabetes Res Clin Pract2007 Sep;77 Suppl 1:S184-9.

18. Moreira CA, Barreto FC, Dempster DW. New insights on diabetes and bone metabolism. J Bras Nefrol2015 Oct-Dec;37(4):490-5.

19. Tavakoli M, Mojaddidi M, Fadavi H, Malik RA. Pathophysiology and treatment of painful diabetic neuropathy. Curr Pain Headache Rep2008 Jun;12(3):192-7.

20. Camargo MR, Barela JA, Nozabieli AJ, Mantovani AM, Martinelli AR, Fregonesi $\mathrm{CE}$. Balance and ankle muscle strength predict spatiotemporal gait parameters in individuals with diabetic peripheral neuropathy. Diabetes Metab Syndr2015 AprJun;9(2):79-84.

21. Sales KLdS, Souza LAd, Cardoso VS. Equilibrio estático de indivíduos com neuropatia periférica diabética. Fisioterapia e Pesquisa2012;19:122-7.

22. Oliveira PP, Fachin SM, Tozatti J, Ferreira MC, Marinheiro LP. Comparative analysis of risk for falls in patients with and without type 2 diabetes mellitus. Rev Assoc Med Bras2012 Mar-Apr;58(2):234-9.

23. Unnikrishnan AG. Approach to a patient with a diabetic foot. Natl Med J India2008 May-Jun;21(3):134-7. 
24. Young MJ, Boulton AJ, MacLeod AF, Williams DR, Sonksen PH. A multicentre study of the prevalence of diabetic peripheral neuropathy in the United Kingdom hospital clinic population. Diabetologia1993 Feb;36(2):150-4.

25. Muir SW, Berg K, Chesworth B, Klar N, Speechley M. Quantifying the magnitude of risk for balance impairment on falls in community-dwelling older adults: a systematic review and meta-analysis. J Clin Epidemiol2010 Apr;63(4):389-406.

26. Miyamoto ST, Lombardi Junior I, Berg KO, Ramos LR, Natour J. Brazilian version of the Berg balance scale. Braz J Med Biol Res2004 Sep;37(9):1411-21.

27. Beauchet O, Fantino B, Allali G, Muir SW, Montero-Odasso M, Annweiler C. Timed Up and Go test and risk of falls in older adults: a systematic review. J Nutr Health Aging2014 Dec;15(10):933-8.

28. (Ministério da Saúde (BR). Hipertensão Arterial Sistêmica e Diabetes Mellitus. Protocolo. Brasília: Ministério da Saúde; 2001. (Cadernos de Atenção Básica, 7). 


\section{APÊNDICE A}

Questionário

\section{IDENTIFICAÇÃo}

Obs.: deve ter entre 50 e 70 anos

Obs.2: Serão excluídos dessa avalição os pacientes que possam apresentar outras causas para a neuropatia como as seguintes listadas: insuficiência renal, hipotireoidismo, história de etilismo, tabagismo, deficiência de ácido fólico, síndromes paraneoplásicas, uso de antidepressivos ou sedativos, ou ainda, concomitância de outros sintomas neurológicos ainda em investigação que se encaixem em outras síndromes neurológicas serão interrogados.

Nome:

Tel:

Endereço:

NOSES:

$R G$ :

DN: $\quad$ Idade: $\quad$ Sexo: $\square \mathrm{M} \square \mathrm{F}$

Escolaridade:

Profissão:

Estimativa da renda familiar:

Número de pessoas residentes na mesma moradia:

Tipo de moradia:

Data da Coleta: 


\section{* DADOS ANTROPOMÉTRICOS}

Peso: Altura: cm IMC:

Circunferência abdominal: $\mathrm{cm}$

Realiza atividade física? $\square \operatorname{Sim} \square$ Não

Qual?

Quanto tempo por semana? $\mathrm{min} / \mathrm{semana}$ (obs: atividade regular $=150 \mathrm{~min} / \mathrm{semana}$ )

* ANTECEDENTES PESSoAis

Etilismo: $\square \operatorname{SIM} \square$ NÃO

Tabagismo: $\square$ SIM $\square$ NÃO $\square$ Ex-tabagista

* DADOS ESPECÍFICOS DA DOENÇA - DM2

Medicações prévias:

Medicações atuais:

Tempo do diagnóstico:

No momento apresenta:

Poliúria: $\square \operatorname{SIM} \square$ NÃO

Polidipsia: $\square$ SIM $\square$ NÃO

Emagrecimento: $\square$ SIM $\square$ NÃO

Histórico de úlceras no pé: $\square$ SIM $\square$ NÃO 
* QUEDAS

Houve queda no último ano? $\square \operatorname{SIM} \square$ NÃO

Se sim, houve fratura? $\square$ SIM. Local___ $\square$ NÃO

* COMORBIDADES

$\square$ HAS $\square$ Osteoporose $\square$ Dislipidemia $\square$ Hipotireoidismo $\square$ HIV

Outras:

\section{* CONTROLE GLICÊMICO}

Último nível de glicemia de jejum:

Última glicemia pós prandial:

Última hemoglobina glicada:

Hemoglobinas glicadas anteriores (se disponível) - até 3 medidas:

\section{TESTES ESPECÍfICOS}

\section{Achados da inspeção:}

Ausência de deformidades, calos, rachaduras, micoses, laceração da pele, coloração normal

Toque:

Temperatura normal, turgor normal 
Palpação dos pulsos:

Tibial anterior:

Pedioso:

Achados do teste de monofilamento:

Sensibilidade

Esquerdo

Pododáctilo

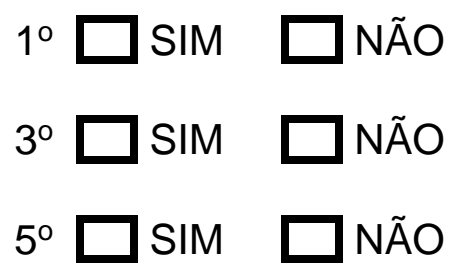

Metatarso

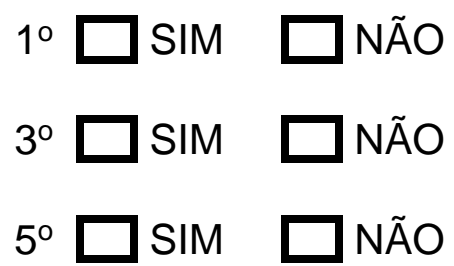

Direito

Pododáctilo

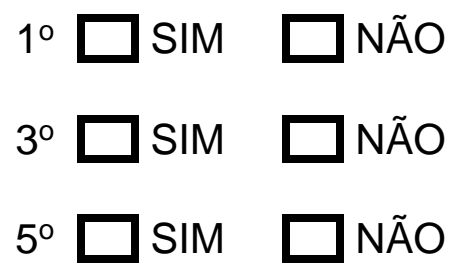

Metatarso

$1^{\circ} \square \operatorname{SIM} \square$ NÃO

$3^{\circ} \square \operatorname{SIM} \square$ NÃO

$5^{\circ} \square \operatorname{SIM} \square$ NÃO 
Total: (/12)

\section{TESTE TUG}

Resultado:

1) Levantar de uma poltrona

2) Caminhar 3 metros (cerca de 6 passos)

3) Andar para trás

4) Sentar-se novamente

5) Total: 


\section{ANEXO A}

Termo de Consentimento Livre e Esclarecido (TCLE)

"Avaliação clínica do risco de quedas com e sem fraturas em pacientes com neuropatia diabética"

Instituição das pesquisadoras: UniCEUB

Pesquisadora responsável [professora orientadora, graduada]: Gabriela Resende Vieira de Sousa

Pesquisadoras assistentes [alunas de graduação]: Mariana Carvalho Gomes; Mariana França Bandeira de Melo

Você está sendo convidado(a) a participar do projeto de pesquisa acima citado. $\mathrm{O}$ documento abaixo contém todas as informações necessárias sobre a pesquisa que estamos fazendo. Sua colaboração neste estudo será de muita importância para nós, mas se desistir a qualquer momento, isso não causará nenhum prejuízo.

O nome deste documento que você está lendo é Termo de Consentimento Livre e Esclarecido (TCLE).

Antes de decidir se deseja participar (de livre e espontânea vontade) você deverá ler e compreender todo o conteúdo. Ao final, caso decida participar, você será solicitado a assiná-lo e receberá uma cópia do mesmo.

Antes de assinar, faça perguntas sobre tudo o que não tiver entendido bem. A equipe deste estudo responderá às suas perguntas a qualquer momento (antes, durante e após o estudo).

\section{Natureza e objetivos do estudo}

- O objetivo deste estudo é avaliar a prevalência de neuropatia associada ao risco de quedas e/ou fraturas em pacientes com diagnóstico de Diabetes 
Mellitus tipo 2 que fazem acompanhamento neste Centro de Saúde, assim como suas características clínicas e sociais mais importantes.

- Você está sendo convidado a participar exatamente por se enquadrar no perfil de pacientes que gostaríamos de avaliar (critérios: ter o diagnóstico de Diabetes Mellitus tipo 2 e ter entre 50 e 70 anos)

\section{Procedimentos do estudo}

- Sua participação consiste em ser submetido a testes simples que avaliam o seu equilíbrio e estabilidade postural; eventualmente as pesquisadoras poderão entrar em contato por telefone para saber se sofreu alguma queda ou fratura.

- Não haverá nenhuma outra forma de envolvimento ou comprometimento neste estudo.

- A pesquisa será realizada no Centro de Saúde em que você é acompanhado.

\section{Riscos e benefícios}

- Este estudo possui baixíssimo risco que é inerente aos testes de equilíbrio (levantar-se, sentar-se, permanecer em pé parado com os olhos fechados, etc.)

- Medidas preventivas durante os testes de equilíbrio serão tomadas para minimizar qualquer risco ou incômodo.

- Caso esse procedimento possa gerar algum tipo de constrangimento você não precisa realizá-lo.

- Sua participação poderá ajudar no maior conhecimento sobre a diabetes e suas complicações, principalmente a neuropatia. Pretendemos traçar estratégias para prevenção das quedas nesses pacientes.

\section{Participação, recusa e direito de se retirar do estudo}

- Sua participação é voluntária. Você não terá nenhum prejuízo se não quiser participar.

- Você poderá se retirar desta pesquisa a qualquer momento, bastando para 
isso entrar em contato com uma das pesquisadoras responsáveis.

- Conforme previsto pelas normas brasileiras de pesquisa com a participação de seres humanos você não receberá nenhum tipo de compensação financeira pela sua participação neste estudo.

\section{Confidencialidade}

- Seus dados serão manuseados somente pelas pesquisadoras e não será permitido o acesso a outras pessoas.

- O material com as suas informações ficará guardado sob a responsabilidade das pesquisadoras com a garantia de manutenção do sigilo e confidencialidade. Os dados e instrumentos utilizados ficarão arquivados com a pesquisadora responsável por um período de 5 anos, e após esse tempo serão destruídos.

- Os resultados deste trabalho poderão ser apresentados em encontros ou revistas científicas, entretanto, ele mostrará apenas os resultados obtidos como um todo, sem revelar seu nome, instituição a qual pertence ou qualquer informação que esteja relacionada com sua privacidade.

Se houver alguma consideração ou dúvida referente aos aspectos éticos da pesquisa, entre em contato com o Comitê de Ética em Pesquisa do Centro Universitário de Brasília - CEP/UniCEUB, que aprovou esta pesquisa, pelo telefone 3966.1511 ou pelo e-mail cep.uniceub@uniceub.br. Também entre em contato para informar ocorrências irregulares ou danosas durante a sua participação no estudo.

$\mathrm{Eu}$, $R G$

após receber uma explicação completa dos objetivos do estudo e dos procedimentos envolvidos concordo voluntariamente em fazer parte deste estudo.

Este Termo de Consentimento encontra-se impresso em duas vias, sendo que uma cópia será arquivada pelo pesquisador responsável, e a outra será fornecida ao senhor(a). 
Brasília, de de

Participante

Gabriela Resende Vieira de Sousa, celular (61) 8137-3201

Mariana Carvalho Gomes, te le f o ne celular (61) 9176-5092, e-mail: carvalhogomesmari@gmail.com

Mariana França Bandeira de Melo, te le f o ne celular (61) 9609-9084, e-mail: marifrancabm@gmail.com

\section{Endereço dos(as) responsável(eis) pela pesquisa:}

Instituição: UniCEUB

Endereço: SEPN 707/907 - Campus do UniCEUB

Bairro: /CEP/Cidade: Asa Norte, CEP 70790-075, Brasília -DF

\section{Endereço do(a) participante-voluntário(a)}

Domicílio: (rua, praça, conjunto): 
Bloco: /№: /Complemento:

Bairro: /CEP/Cidade: /Telefone:

Ponto de referência: 


\section{ANEXO B}

\section{ESCALA DE EQUILÍBRIO FUNCIONAL DE BERG}

\section{Posição sentada para posição em pé}

( ) 4 capaz de levantar-se sem utilizar as mãos e estabilizar-se independentemente

( ) 3 capaz de levantar-se independentemente utilizando as mãos

( ) 2 capaz de levantar-se utilizando as mãos após diversas tentativas

( ) 1 necessita de ajuda mínima para levantar-se ou estabilizar-se

( ) 0 necessita de ajuda moderada ou máxima para levantar-se

\section{Permanecer em pé sem apoio}

( ) 4 capaz de permanecer em pé com segurança por 2 minutos

( ) 3 capaz de permanecer em pé por 2 minutos com supervisão

( ) 2 capaz de permanecer em pé por 30 segundos sem apoio

( ) 1 necessita de várias tentativas para permanecer em pé por 30 segundos sem apoio

( ) 0 incapaz de permanecer em pé por 30 segundos sem apoio

\section{Posição em pé para posição sentada}

( ) 4 senta-se com segurança com uso mínimo das mãos

( ) 3 controla a descida utilizando as mãos

( ) 2 utiliza a parte posterior das pernas contra a cadeira para controlar a descida

( ) 1 senta-se independentemente, mas tem descida sem controle

( ) 0 necessita de ajuda para sentar-se 


\section{Permanecer sentado sem apoio nas costas, mas com os pés apoiados no chão ou num banquinho}

( ) 4 capaz de permanecer sentado com segurança e com firmeza por 2 minutos

( ) 3 capaz de permanecer sentado por 2 minutos sob supervisão

( ) 2 capaz de permanecer sentado por 30 segundos

( ) 1 capaz de permanecer sentado por 10 segundos

( ) 0 incapaz de permanecer sentado sem apoio durante 10 segundos

\section{Transferências}

( ) 4 capaz de transferir-se com segurança com uso mínimo das mãos

( ) 3 capaz de transferir-se com segurança com o uso das mãos

( ) 2 capaz de transferir-se seguindo orientações verbais e/ou supervisão

( ) 1 necessita de uma pessoa para ajudar

( ) 0 necessita de duas pessoas para ajudar ou supervisionar para realizar a tarefa com segurança

\section{Permanecer em pé sem apoio com os olhos fechados}

( ) 4 capaz de permanecer em pé por 10 segundos com segurança

( ) 3 capaz de permanecer em pé por 10 segundos com supervisão

( ) 2 capaz de permanecer em pé por 3 segundos

( ) 1 incapaz de permanecer com os olhos fechados por 3 segundos, mas mantém-se em pé

( ) 0 necessita de ajuda para não cair 


\section{Permanecer em pé sem apoio com os pés juntos}

( ) 4 capaz de posicionar os pés juntos independentemente e permanecer por 1 minuto com segurança

( ) 3 capaz de posicionar os pés juntos independentemente e permanecer por 1 minuto com supervisão

( ) 2 capaz de posicionar os pés juntos independentemente e permanecer por 30 segundos

( ) 1 necessita de ajuda para posicionar-se, mas é capaz de permanecer com os pés juntos durante 15 segundos

( ) 0 necessita de ajuda para posicionar-se e é incapaz de permanecer nessa posição por 15 segundos

\section{Alcançar a frente com o braço estendido permanecendo em pé}

( ) 4 pode avançar à frente mais que $25 \mathrm{~cm}$ com segurança

( ) 3 pode avançar à frente mais que $12,5 \mathrm{~cm}$ com segurança

( ) 2 pode avançar à frente mais que $5 \mathrm{~cm}$ com segurança

( ) 1 pode avançar à frente, mas necessita de supervisão

( ) 0 perde o equilíbrio na tentativa, ou necessita de apoio externo

\section{Pegar um objeto do chão a partir de uma posição em pé}

( ) 4 capaz de pegar o chinelo com facilidade e segurança

( ) 3 capaz de pegar o chinelo, mas necessita de supervisão

( ) 2 incapaz de pegá-lo, mas se estica até ficar a $2-5 \mathrm{~cm}$ do chinelo e mantém o equilíbrio independentemente

( ) 1 incapaz de pegá-lo, necessitando de supervisão enquanto está tentando 
( ) 0 incapaz de tentar, ou necessita de ajuda para não perder o equilíbrio ou cair

10. Virar-se e olhar para trás por cima dos ombros direito e esquerdo enquanto permanece em pé

( ) 4 olha para trás de ambos os lados com uma boa distribuição do peso

( ) 3 olha para trás somente de um lado, o lado contrário demonstra menor distribuição do peso

( ) 2 vira somente para os lados, mas mantém o equilíbrio

( ) 1 necessita de supervisão para virar

( ) 0 necessita de ajuda para não perder o equilíbrio ou cair

\section{Girar 360 graus}

( ) 4 capaz de girar 360 graus com segurança em 4 segundos ou menos

( ) 3 capaz de girar 360 graus com segurança somente para um lado em 4 segundos ou menos

( ) 2 capaz de girar 360 graus com segurança, mas lentamente

( ) 1 necessita de supervisão próxima ou orientações verbais

( ) 0 necessita de ajuda enquanto gira

12. Posicionar os pés alternadamente no degrau ou banquinho enquanto permanece em pé sem apoio

( ) 4 capaz de permanecer em pé independentemente e com segurança, completando 8 movimentos em 20 segundos

( ) 3 capaz de permanecer em pé independentemente e completar 8 movimentos em mais que 20 segundos

( ) 2 capaz de completar 4 movimentos sem ajuda 
( ) 1 capaz de completar mais que 2 movimentos com o mínimo de ajuda

( ) 0 incapaz de tentar, ou necessita de ajuda para não cair

\section{Permanecer em pé sem apoio com um pé à frente}

( ) 4 capaz de colocar um pé imediatamente à frente do outro, independentemente, e permanecer por 30 segundos

( ) 3 capaz de colocar um pé um pouco mais à frente do outro e levemente para o lado, independentemente, e permanecer por 30 segundos

( ) 2 capaz de dar um pequeno passo, independentemente, e permanecer por 30 segundos

( ) 1 necessita de ajuda para dar o passo, porém permanece por 15 segundos

( ) 0 perde o equilíbrio ao tentar dar um passo ou ficar de pé

\section{Permanecer em pé sobre uma perna}

( ) 4 capaz de levantar uma perna independentemente e permanecer por mais que 10 segundos

( ) 3 capaz de levantar uma perna independentemente e permanecer por 5-10 segundos

( ) 2 capaz de levantar uma perna independentemente e permanecer por mais que 3 segundos

( ) 1 tenta levantar uma perna, mas é incapaz de permanecer por 3 segundos, embora permaneça em pé independentemente

( ) 0 incapaz de tentar, ou necessita de ajuda para não cair

( ) Escore total (Máximo $=56$ ) 

